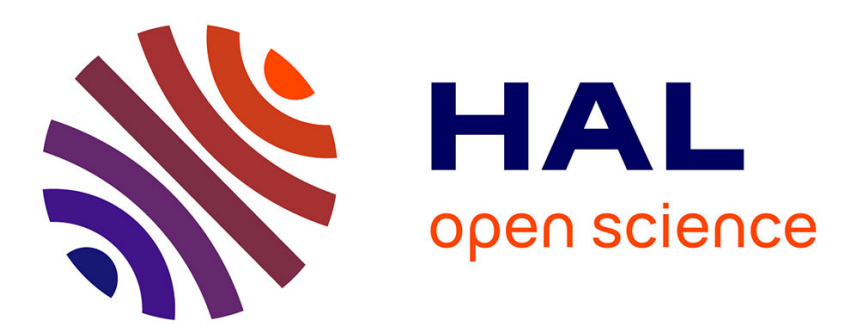

\title{
Calibrating pollutant dispersion in 1-D hydraulic models of river networks
}

M. Launay, J. Le Coz, B. Camenen, C. Walter, H. Angot, Guillaume Dramais, J.B. Faure, Marina Coquery

\section{- To cite this version:}

M. Launay, J. Le Coz, B. Camenen, C. Walter, H. Angot, et al.. Calibrating pollutant dispersion in 1-D hydraulic models of river networks. Journal of Hydro-environment Research, 2015, 9 (1), pp.120-132. 10.1016/j.jher.2014.07.005 . hal-01118986

\section{HAL Id: hal-01118986 \\ https://hal.science/hal-01118986}

Submitted on 20 Feb 2015

HAL is a multi-disciplinary open access archive for the deposit and dissemination of scientific research documents, whether they are published or not. The documents may come from teaching and research institutions in France or abroad, or from public or private research centers.
L'archive ouverte pluridisciplinaire HAL, est destinée au dépôt et à la diffusion de documents scientifiques de niveau recherche, publiés ou non, émanant des établissements d'enseignement et de recherche français ou étrangers, des laboratoires publics ou privés. 


\title{
Calibrating pollutant dispersion in 1-D hydraulic models of river networks
}

\author{
M. Launay ${ }^{\mathrm{a}}$, J. Le Coz ${ }^{* a}$, B. Camenen ${ }^{\mathrm{a}}$, C. Walter ${ }^{\mathrm{a}}$, H. Angot ${ }^{\mathrm{b}}$, G. Dramais ${ }^{\mathrm{a}}$, J.-B. Faure ${ }^{\mathrm{a}}$, M. Coquery ${ }^{\mathrm{b}}$ \\ ${ }^{a}$ Irstea, UR HHLY, Hydrology-Hydraulics, 5 rue de la Doua - CS 70077 - F-69626 Villeurbanne, France. \\ ${ }^{b}$ Irstea, UR MALY, Freshwater Systems Ecology and Pollution, 5 rue de la Doua - CS 70077 - F-69626 Villeurbanne, France.
}

\begin{abstract}
The objective of this article is to investigate the major issues associated with the calibration of the pollutant dispersion in 1-D hydraulic models applied to river networks, especially large, complex, artificialized ones where ecological and socio-economical threats are important. Such issues are illustrated and discussed using the results of five fluorescent tracer experiments conducted in contrasted open-channel systems, ranging from a simple trapezoidal canal to a more complex river network. Experimental dispersion values were quantified using both the change of moment method and a simple fit-by-eye procedure for eight river reaches with homogeneous hydraulic conditions and an achieved tracer mixing and dispersive equilibrium. Since dispersion coefficient values depend on the assumed dispersion model, ideally they should be calibrated using the same model in which they are to be used, as was done in this study. We also derived concurrent longitudinal dispersion values using the velocity field measured by hydro-acoustic profilers (ADCP), which appears as a promising and cost-efficient technique for documenting dispersion in large river systems. It appears that the formulae for which the fit was mainly based on the cross-sectional aspect ratio are generally more appropriate for field data than those which are sensitive to the velocity to shear velocity ratio. The interpretation of complex dispersion and mixing processes, along with the selection of relevant dispersion coefficient predictors are key to minimizing errors in the numerical simulation of pollution dynamics in river networks.
\end{abstract}

Key words: longitudinal dispersion, river, pollution, 1-D hydraulic modelling, ADCP

\section{Introduction}

The pollution of rivers due to accidental spills represents a major threat to ecology and to various uses of water [33]. The environmental management of river systems requires accurate and efficient tools to predict pollutant concentration, propagation and dispersion, especially near water intakes when rivers are used as a source of drinking water [4]. A commonly used tool is numerical modelling, which is developed to simulate the hydraulic conditions and the transport and fate of solute or particulate pollutants along river systems $[17,15,36,30]$.

At the river network scale, the application of two- and three-dimensional transport models is generally not appropriate because of their time consuming computations [33] and because of the lack of data for the construction of such models and their validation. One-dimensional (1-D) transport models are generally preferred for real-time predictions of the spatio-temporal dynamics of a pollution in large river networks. While simple, most 1-D models are able to simulate complex, multi-reach hydraulic networks, including artificial structures as well as bifurcations and confluences.

In conventional 1-D hydraulic models, the transport of a fully mixed, passive pollutant or tracer is described by the 1-D advection-dispersion equation, also known as the Fickian model [40, 33]:

$$
\frac{\partial C}{\partial t}+U \frac{\partial C}{\partial x}=D_{L} \frac{\partial^{2} C}{\partial x^{2}}
$$

\footnotetext{
${ }^{*}$ Corresponding author. Tel: +33 472208786; fax: +33478477875

Email address: jerome. lecoz@irstea.fr (J. Le Coz)
} 
in which $C$ is the section-averaged concentration, $t$ the time, $U$ the section-averaged velocity, $x$ the distance in the longitudinal direction, and $D_{L}$ the longitudinal dispersion coefficient. The Fickian model for longitudinal dispersion applies when dispersive equilibrium is reached, i.e. when the effects of velocity shear are balanced by the effect of turbulent mixing [39]. Downstream of the injection point (or transverse line), this condition is achieved in the equilibrium zone, which establishes after the so-called advective zone. Equilibrium is reached when the tracer has sampled the entire flow, which generally occurs after the tracer concentration is homogeneous throughout the cross-section. However, this is not a sufficient condition for checking dispersion equilibrium.

In rivers and canals, longitudinal dispersion is mainly due to vertical and transverse velocity gradients, while molecular diffusion and turbulent diffusion are generally negligible. According to the literature, the longitudinal dispersion varies within a range of $10^{-1}$ to $10^{7} \mathrm{~m}^{2} / \mathrm{s}[20,34,27,41]$, while the molecular and turbulent diffusion are in the order of $10^{-9}$ and $10^{-2} \mathrm{~m}^{2} / \mathrm{s}$, respectively [39]. Note that turbulent diffusion may vary from $10^{-3}$ to $1 \mathrm{~m}^{2} / \mathrm{s}$, according to the hydraulic conditions. Usually, in rivers vertical velocity gradient effects on longitudinal dispersion are negligible compared to transverse velocity gradient effects [22]. It is therefore possible to accurately estimate longitudinal dispersion in natural streams from the transverse velocity profile, as done by Seo and Baek [42] by fitting a beta function to the observed velocity distribution.

Other mechanisms, such as trapping in recirculation zones, laminar boundary layers or porous media, can also cause dispersion. Such processes are usually designated as transient storage effects. Indeed, the observed "tails" of breakthrough curves are often longer than can be accounted for by Eq. 1 applied analytically to solute tracer pulses [37]. Hence, Bencala and Walters [5] introduced the effect of the transient storage in the right-hand side of Eq. 1. Such model has been widely used to better understand physical processes in experimental results (Cheong and Seo [12], Gooseff et al. [24], Wörman and Wachniew [51], Bottacin-Busolin et al. [6], Szeftel et al. [48] among others). However, it remains difficult to be applied in predictive models since it introduces two additional variables (solute concentration and crosssection area of the storage zone) and one additional parameter (stream storage exchange coefficient), which may be difficult to evaluate. Moreover, in large river cases dead-zones may be less relevant than in the small rough streams studied in the literature focussing on transient storage mechanisms.

In 1-D hydraulic models, the longitudinal dispersion coefficient has to be predicted through formulae accounting for the mainstream longitudinal dispersion, usually ignoring the transient storage effects that were highlighted by research in the last decades [39]. Such semi-empirical formulae were established against experimental data sets to relate the longitudinal dispersion coefficient to the bulk characteristics of the flow. However, the predictive accuracy of such formulae is often questionable, which can be explained by the scatter and lack of representativeness of the underlying data set.

Soluble tracer experiments are the most direct method to collect field data on longitudinal dispersion in rivers [26]. Passive tracers injected into a stream behave in the same way as conservative pollutants and their monitoring is feasible using either in-situ recording instruments or water samples to be analysed in the laboratory. An ideal tracer should be readily water soluble, easily detectable, harmless at low concentrations, stable, and inexpensive [13, 50, 18]. However, field data remain scarce in large river networks, mainly due to the logistical difficulty and the high cost of tracing operations. Most large-scale river tracer tests were performed in the 1960s and 1970s [50]. Among recent studies at a large scale (i.e. at least $10 \mathrm{~km}$ length), those performed on the Hudson River, USA [25, 8], in several Portuguese rivers [15] and on the Narew River, Poland [38] should be mentioned.

In recent years, some authors $[9,43,31]$ used ADCP data in order to compute the longitudinal sheardriven dispersion at a cross-section of a river. For two decades indeed, acoustic Doppler current profilers (ADCP) have been increasingly used by hydrometric services to efficiently measure discharge in rivers. The most common procedure is the mobile-boat method for which the vessel-mounted ADCP scans both flow depth and velocity field during a crossing of the river section. While the derivation of longitudinal dispersion from the velocity field throughout a cross-section was known for long [22], velocity sampling by ADCP offers an attractive and cost-efficient solution for measuring dispersion in rivers, especially in the largest ones.

The objective of this article is to investigate the major issues associated with the calibration of pollutant dispersion in 1-D hydraulic models applied to river networks, especially large, complex, artificialized ones where ecological and socio-economical threats are important. From the modeller's standpoint, the 
Table 1: Values of the parameters in empirical formulas for the estimation of longitudinal dispersion coefficient (Eq. 2)

\begin{tabular}{l|lll} 
Authors & $a$ & $b$ & $c$ \\
\hline & & & \\
Elder [16] & 5.93 & 0 & 0 \\
Fischer [21] & 0.011 & 2 & 2 \\
Liu [34] & 0.18 & 0.5 & 2 \\
Iwasa and Aya [27] & 2 & 0 & 1.5 \\
Seo and Cheong [41] & 5.915 & 1.428 & 0.62 \\
Koussis and Rodriguez-Mirasol [32] & 0.6 & 0 & 2
\end{tabular}

major questions are the following: Is most of the pollutant fully mixed and is the dispersive equilibrium reached so that the Fickian model applies? Are transient storage effects negligible or would they require the consideration of additional terms? How accurate are the dispersion coefficient values predicted by conventional formulae, and how sensitive are the modelling results to the choice of a formula? Such issues are illustrated and discussed using the results of new, comprehensive fluorescent tracer experiments, with concurrent ADCP-based velocity surveys and dispersion estimation.

\section{Longitudinal dispersion in 1-D river models}

\subsection{Numerical simulation tools}

In this study, the river systems were simulated using Mage, a typical 1-D loop-meshed hydrodynamic code [46] with AdisTS, an advection-dispersion resolution for pollutant and suspended-sediment transport [1]. Mage is a 1-D hydrodynamic model simulating flow in transient regime. The 1-D Barré de SaintVenant equations (shallow water equations) are solved using a four point finite difference scheme. The real geometry of the river bed is represented by a set of cross-sections that is used for the calculation. The network topology may be looped to represent islands or multi-branched networks with confluences and bifurcations. This model presents very low computation times, which allow for real-time simulation or simulation of long time series [1]. The partitioning of discharges at bifurcations is governed either by the geometry of the river bed or by the representation of flow controlling structures such as dams.

AdisTS solves the Fickian model (Eq. 1), using a numerical resolution of the advection-dispersion equation which is based on operator splitting. The advection part is solved using a TVD scheme (Total Variation Diminishing) with the Superbee flux limiter and is adapted to non uniform space steps. This scheme is well known to dramatically reduce the numerical dispersion. AdisTS allows the user either to set a fixed value for $D_{L}$ or to use a predictive formula, by setting the $a, b$, and $c$ calibration parameters of the following equation:

$$
\frac{D_{L}}{H U_{*}}=a\left(\frac{U}{U_{*}}\right)^{b}\left(\frac{W}{H}\right)^{c}
$$

where $W$ is the river width, $H$ is the section-averaged water depth, $U_{*}=\sqrt{\tau / \rho}$ is the shear velocity, $\tau$ the section-averaged bed shear stress, $\rho$ the water density. Different authors have established numerous empirical formulae of this type, based on a dimensional analysis of the dispersion coefficient. Since longitudinal dispersion in open channels is mainly driven by velocity gradients and turbulent mixing, the main control factors are the $U / U_{*}$ ratio, which captures turbulent shear intensity, and the $W / H$ aspect ratio, which captures the transversal velocity gradient and the secondary currents intensity. The different authors suggested contrasted values for parameters $a, b$, and $c$ as presented in Table 1 . From the following review of the literature, it is a relevant question whether conventional formulae do accurately predict the real Fickian dispersion coefficient values, especially in large river systems.

\subsection{Review of predictive formulae used in 1-D models}

Most of the authors who suggested an empirical formula in the form of Eq. 2 used a very similar data set. Seo and Cheong [41] gave a listing of these data, which mainly correspond to measurements in US rivers 
Table 2: Comparison of the empirical formulae performances using experimental data from the literature

\begin{tabular}{l|cccc} 
Authors / formula & $\operatorname{mean}(\mathrm{E})$ & $\mathrm{std}(\mathrm{E})$ & $G 2(\%)$ & $G 5(\%)$ \\
\hline Elder [16] & -1.87 & 0.86 & 5 & 7 \\
Fischer [21] & 0.23 & 0.81 & 3 & 62 \\
Liu [34] & 0.26 & 0.55 & 46 & 78 \\
Iwasa and Aya [27] & 0.1 & 0.65 & 45 & 83 \\
Seo and Cheong [41] & 0.27 & 0.56 & 51 & 84 \\
Koussis and Rodriguez-Mirasol [32] & 0.38 & 0.67 & 39 & 69
\end{tabular}

during the sixties and early seventies. In order to investigate more situations, we added laboratory data from Fischer [19], and additional field data from Carr and Rehmann [9] to the data set. Although a large scatter is observed, Fig. 1 clearly indicates positive values for the coefficients $b$ (Fig. 1b) and $c$ (Fig. 1a), respectively, as observed by several authors. However, because of the scatter and because of the lack of data for extreme values of the parameters $W / H$ and $U / U_{*}$, it is very difficult to assess an accurate value for $b$ or $c$.

In Fig. 1a, laboratory data appear to follow the same trend as field data according to $W / H$, which indicates their efficiency in scaling the geometry effects observed in the field. Conversely, in Fig. 1b it appears that the cluster of laboratory data corresponding to narrow channels $(\circ, W / H<30)$ yields lower $D_{L}$ values compared to field experiments with similar $U / U_{*}$ values, which indicates that roughness is not properly scaled in laboratory experiments. This may be due to a scaling effect of edge roughness, because flow regimes are different: smooth flow regimes in the laboratory experiments may not be fully representative of rough turbulent flows in natural conditions.

Four scores were used to estimate the performance of the proposed formulae in predicting the longitudinal dispersion values of the experimental data set. We calculated the mean value, mean(E), and the standard deviation, std(E), of the error function $E$ defined as follows:

$$
E=\log _{10}\left(\frac{D_{L, \text { pred }}}{D_{L, \text { exp }}}\right)
$$

where $D_{L, p r e d}$ and $D_{L, \exp }$ are the predicted and experimental values of the longitudinal dispersion coefficient, respectively. Additionally, we determined the scores $G 2$ and $G 5$ corresponding to the percentage of data points correctly predicted by an equation within a factor 2 or 5 allowed, respectively. The values of mean(E), std(E), G2 and $G 5$ are presented in Table 2 for the different formulae presented in Table 1.

From Table 2, it appears that the Elder equation systematically underestimates the $D_{L}$ values by two orders of magnitude by comparison to the field values (mean $(\mathrm{E})=-1.9)$. Elder [16] adapted the Taylor [49] study of dispersion through a pipe to an open channel of infinite width, assuming a logarithmic distribution of velocity in the vertical direction. This equation does not consider velocity variations in the transversal direction. According to Fischer [19], this may explain the underestimation of the longitudinal dispersion coefficient in natural streams, where the transversal velocity gradient effects are much more important than the vertical velocity gradient effects.

The other formulae studied in this work account for the transversal velocity gradient effects through the $W / H$ ratio. However, they systematically overestimate the value of $D_{L}$ (mean $\left.(\mathrm{E})>0\right)$. With respect to the four scores, the best results are obtained with the formula from Iwasa and Aya [27], then with the formulae from Liu [34] and Seo and Cheong [41]. The formulae of Fischer [21] and Koussis and Rodriguez-Mirasol [32] show poorer performance for most of the four criteria.

\section{Experimental sites and data}

\subsection{Presentation of the five tracer experiments}

The results of five tracer experiments conducted at two sites are used for this study: one experiment in the Gentille canal in 2011 (GE11), and four experiments in the Miribel and Jonage river system in 2000 


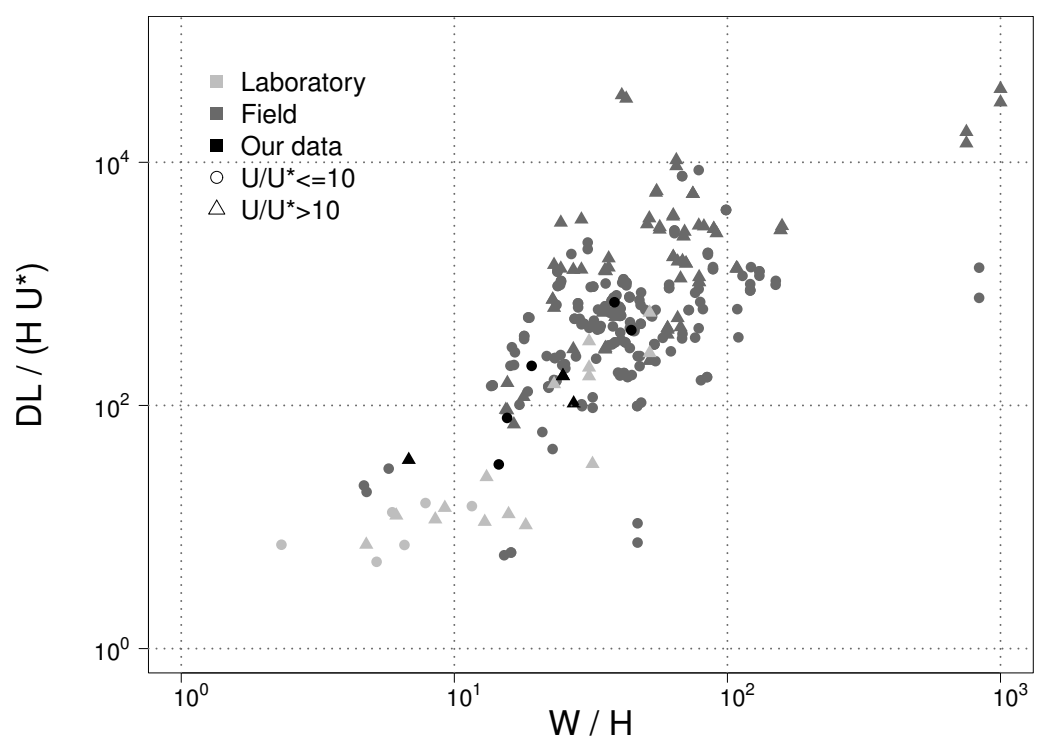

(a)

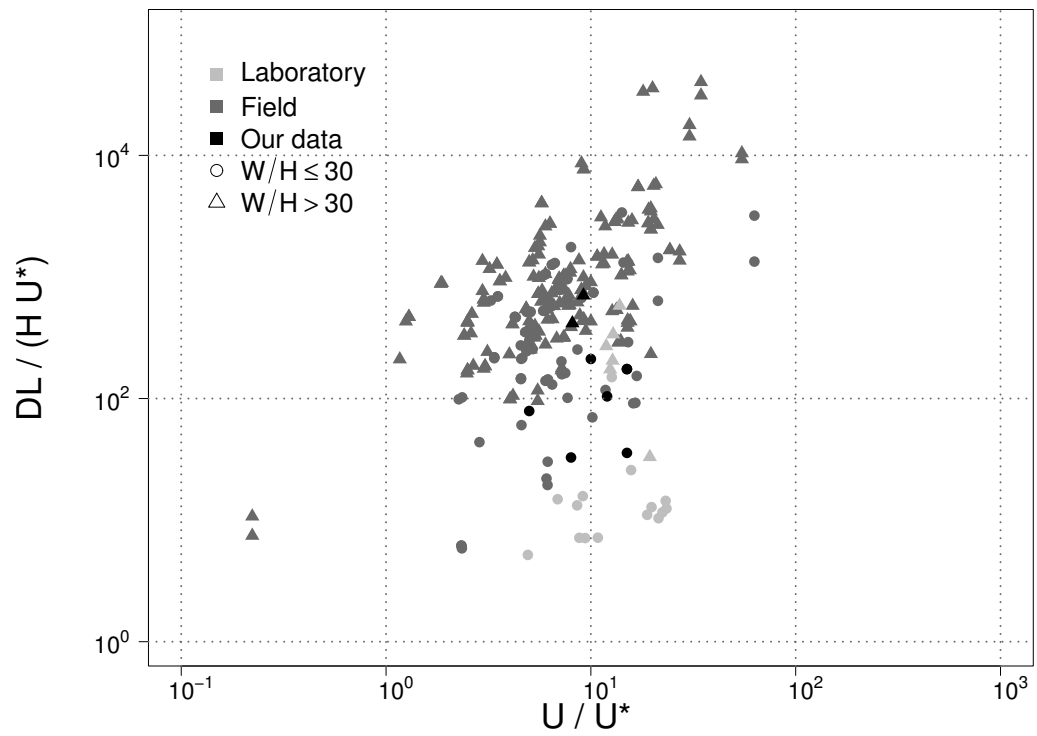

(b)

Figure 1: Variability of the dimensionless longitudinal dispersion coefficient $D_{L} /\left(H U_{*}\right)$ with the aspect ratio, $W / H$ (a) and with the roughness ratio, $U / U_{*}(\mathrm{~b})$. 
(JN00), 2001 (MI01), and 2011 (JN11, MI11). Experimental conditions for the five tracer experiments are summarized in the maps of the experimental sites in Fig. 2, and further details for each experiment are provided in the following paragraphs.

In all experiments, Rhodamine was used as a fluorescent tracer, which is considered as an efficient tracer for large open-channel flows [45]. Whereas Rhodamine B was used in 2000 and 2001 tracer experiments, we preferred Rhodamine WT in 2011 since it is considered much less toxic. Except for the 2000-2001 experiments for which only water sampling was performed to monitor tracer concentrations, the concentration was monitored in situ using several field fluorimeters (Albillia FL30 GGUN) and one fluorimeter in the laboratory (Datalink FL200-R). Field fluorimeters allow for a continuous recording of the river fluorescence level but their quantification limits are poorer $(4 \mu \mathrm{g} / \mathrm{L})$ than those of laboratory devices $(1 \mu \mathrm{g} / \mathrm{L})$. Water sampling and the slightly postponed analysis in the laboratory provided accurate data to calibrate the continuous monitoring by field fluorimeters.

The Gentille Canal (Fig. 2a) is a $14 \mathrm{~m}$ wide, $2 \mathrm{~m}$ deep concrete canal for a hydropower plant on the Garonne River, France. It differs in scale and complexity from the other experimental site. This $2 \mathrm{~km}$ long, trapezoidal canal was used to compare tracer experiments conducted in large rivers with results from a smaller scale stream, with a prismatic geometry and smooth bed and walls. During the tracer experiment, the flow was nearly uniform over the whole reach, and the discharge continuously recorded by ADCP was nearly constant. Rhodamine WT was injected as a slug in the centre of the cross-section. Three to five fluorimeters were hung from bridges and immersed approximately $50 \mathrm{~cm}$ below the surface in order to monitor the lateral mixing of the tracer, as well as its longitudinal propagation and dispersion.

The Miribel and Jonage river system (Fig. 2b and c) is an artificialized section of the Rhône River upstream of Lyon, France. The Miribel and Jonage canals were built in the anastomosing system of the Rhône River during the $\mathrm{XIX}^{\text {th }}$ century. Only a small stretch of the former river bed is remaining, which is called Vieux-Rhône. The bed of these reaches is mainly composed of coarse sediments (grain size varying from 5 to $10 \mathrm{~cm}$ ). Several structures were built for hydropower purpose: Jons dam on the Miribel canal, which in normal hydrological conditions deviates most of the flow to the Jonage canal, and Jonage dam and Cusset hydropower plant situated on the Jonage canal. The Grand Large lake is located along the Jonage canal but a wall made of sheet pile prevents exchanges between the canal and the reservoir. Visual inspection and sampling survey during the experiment confirmed that tracer concentrations in the lake were negligible.

First experiments had been conducted by others in the Miribel and Jonage system in 2001 (Miribel) and in 2000 (Jonage). Unfortunately, the discharge was not continuously recorded within the traced river branches. The discharge in the Miribel channel was claimed to be $30 \mathrm{~m}^{3} / \mathrm{s}$ by the dam managers, which may be underestimated based on our recent direct observations for similar conditions.

The fluorescent tracer Rhodamine B was injected continuously from a bank during one hour at a constant rate, in the vicinity of Jons dam. Manual samples were taken at a limited number of sites as shown in Fig. 2b, for subsequent laboratory analysis of their fluorescence. In spite of the rather poor temporal resolution, the collected data provide valuable indications on the dispersion processes. to determine the dispersion coefficient.

During the experiments conducted in 2011 in Miribel and Jonage channels, the discharges were monitored continuously using vessel-mounted ADCP set up on boats. Discharge was measured at the injection point, at each bifurcation and at the downstream end of hydraulically homogeneous reaches, with a typical uncertainty of 5\%. Discharge in Miribel channel remained constant over the experiment period, whereas discharge in Jonage channel increased from $150 \mathrm{~m}^{3} / \mathrm{s}$ to almost $300 \mathrm{~m}^{3} / \mathrm{s}$. The injection into the Miribel canal was achieved 6 to $7 \mathrm{~km}$ further downstream than the 2000-2001 injections, and the injection point for the Jonage canal was located just downstream of the Jonage dam. For these two experiments, the fluorescent tracer Rhodamine WT was injected from a boat as a slug distributed over a transect line.

Field fluorimeters were either hung from bridges and immersed at mid-depth, or set up from banks on the river bed, as far from the bank as possible. At some monitoring points, two or three fluorimeters were set up at different positions within the same cross-section, in order to verify the complete mixing of tracer across the section. Water sampling was performed either from banks or bridges using plastic buckets or automatic samplers. The sampling frequency was every 10 minutes during the peak concentration and every 30 minutes before and after the peak. The water samples were stored in plastic bottles and transported immediately to the laboratory to be analysed using the laboratory fluorimeter. Specific attention was paid 


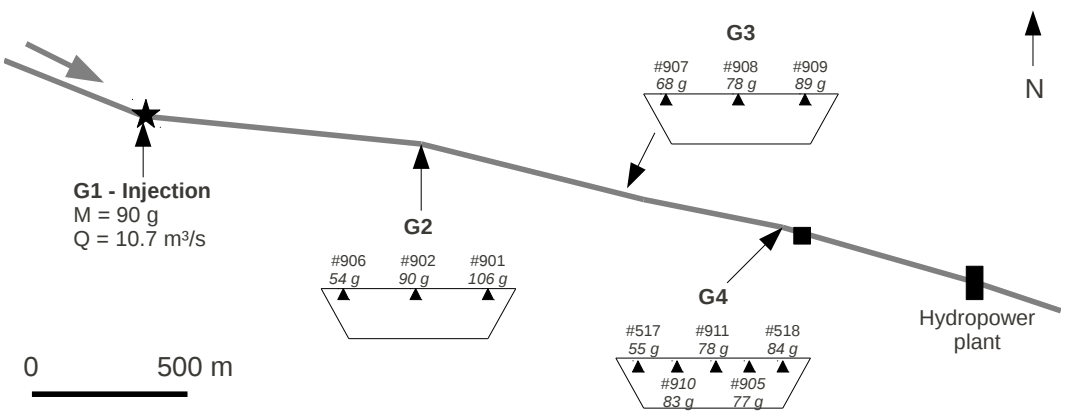

(a)

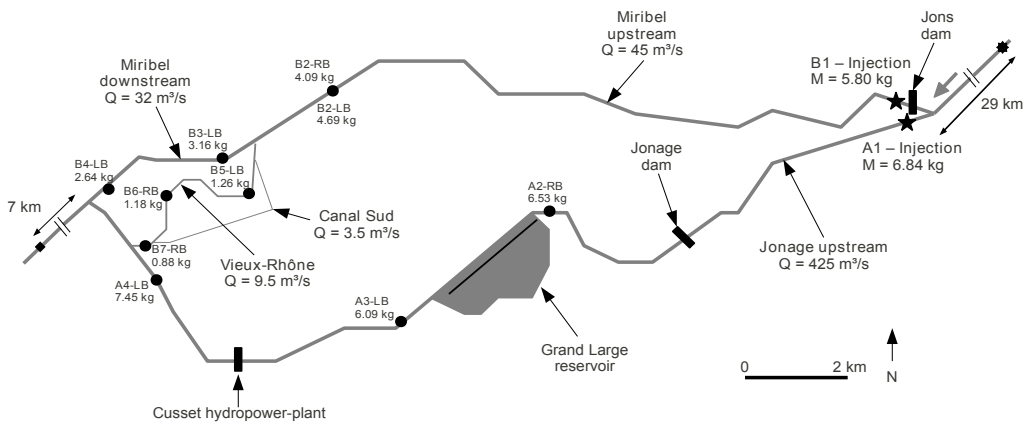

(b)

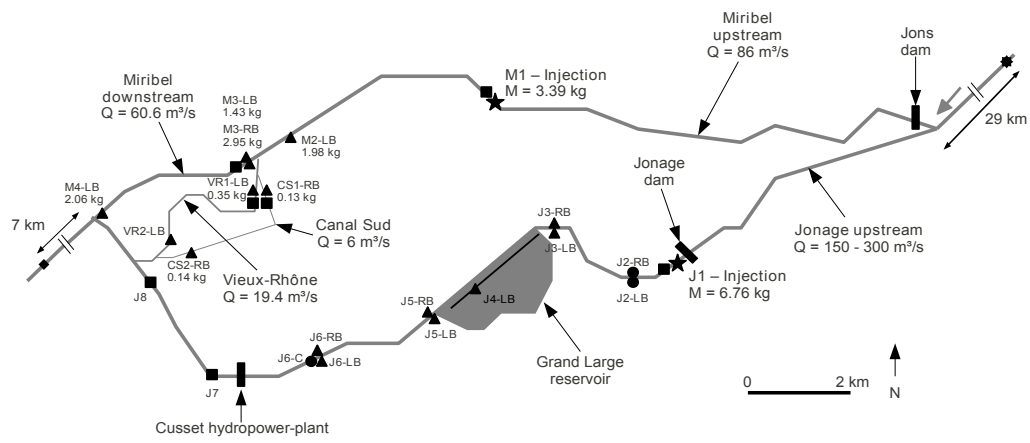

(c)

Figure 2: Schematic maps of the tracer experiments in the Gentille canal in 2011 (a, GE11), in the Jonage and Miribel channels in 2000-2001 (b, JN00, MI01) and in 2011 (c, JN11, MI11). Symbols and abbreviations stand for injection points ( $\star$ ), field fluorimeters $(\boldsymbol{\Lambda})$, manual sampling $(\bullet)$, ADCP measurements $(\boldsymbol{\square})$, discharges $(Q)$, masses $(M)$, left bank (LB), right bank (RB), simulated pollution (cf. Section 5.1 and Fig. 7): injection point (*), and downstream point $(\bullet)$. 
to the transport and storage of samples in order to minimize potential variations of the water characteristics (temperature, light exposure).

\subsection{Assessment of the equilibrium zones}

The breakthrough curves for all the 2011 experiments differ from pure Gaussian curves, especially in that they are skewed (Fig. 3), which had to be expected. Indeed, Rutherford [39] acknowledged that breakthrough curves recorded from laboratory or field experiments are actually never found to be Gaussian. He further explained that this is not only due to transient storage effects by dead zones and laminar near-bed layers, but also notably due to the skewness induced by the propagation of the non-mixed tracer along the advective zone, between the source cross-section and the equilibrium zone.

From our observations downstream of the injection points, and in the absence of significant dead zones or hyporheic flows, the advective effects are the most realistic cause for the skewed breakthrough curves in our tracer experiments.

As explained in the introduction, the Fickian model (Eq. 1) used in most 1-D models applies in the equilibrium zone, downstream of the advective zone. The length of the advective zone, $L_{x}$, may be estimated using the following formula [22, 39]:

$$
L_{x}=\alpha \frac{U L_{t}^{2}}{D_{y}}
$$

with $\alpha=0.3-0.6$ in smooth channels, and $\alpha=1-5$ and even more for rough, small channels. $L_{t}$ is the distance from the maximum velocity point to the nearest bank, and $D_{y}$ is the transverse dispersion coefficient. Following Rutherford [39], we will consider that $L_{t}=0.5-0.7 \mathrm{~W}$ and that $D_{y}=0.3-0.9 H U_{*}$ for irregular but only gently meandering natural channels. We also assume that $\alpha \approx 1$.

The assessment of the advective zone length (Eq. 4), along with verification of the tracer mixing and mass continuity (see e.g. Jobson [28]), will be further used to identify the river reaches where reliable longitudinal dispersion values can be derived from our tracing results. According to Hubbard et al. [26], the transversal and vertical mixing is complete if the areas of the time-concentration curves observed at different points in the cross-section are the same. Differences across a river section in the times of peak concentration and in the shapes of breakthrough curves also provide information on mixing and equilibrium.

\subsection{Review of the exploitable tracing results}

Eight reaches (see Table 4) were selected where hydraulic conditions were found to be nearly uniform, and where sufficient mixing and tracer equilibrium were checked, according to the methods described in the previous section. Fig. 2 presents the masses computed from the concentration curves recorded by each fluorimeter for all tracer experiments. The $L_{x}$ distances computed with Eq. 4 are also reported in Table 4.

In the Gentille canal, the distances between the injection point and the sampling positions are greater than $L_{x}$, which suggests that dispersive equilibrium should be acceptably achieved in this canal. However, the concentrations recorded on the right part of the flow remained slightly higher than on the left part at all monitoring stations along the reach (Fig. 3a).

Full mixing was more questionable in the Miribel canal experiments. In 2001, the distance from the injection position B1 to the bifurcation B2 between the Miribel canal and the Vieux-Rhône stream (Fig. 2b) is slightly larger than $L_{x}$. It can therefore be reasonably assumed that mixing was at least partially reached, though not totally. The difference between the injected mass and that recorded at B2 may be explained by the uncertainty in the discharge claimed by the dam manager and used for the calculation.

While mass continuity is observed in 2001 at the bifurcation between Miribel canal and the VieuxRhône, the masses recorded in 2011 at M3-LB and M3-RB are not equivalent (see Fig. 2c). The breakthrough curves along Miribel channel (Fig. 3b) show different shapes and times of the peak concentration, according to the measurement positions. This is consistent with the fact that in 2011 the distance between the injection point and the bifurcation was shorter than in 2001, and smaller than $L_{x}$. Experimental data in the downstream part of Miribel channel in 2011 should therefore be interpreted carefully, considering the incomplete transversal mixing at M3.

Based on the comparison of tracer masses, full mixing seems to be achieved in the Vieux-Rhône in 2001 (Fig. 2b) and in the Vieux-Rhône and Canal Sud area for the 2011 experiments (Fig. 2b and Fig. 3c). The 


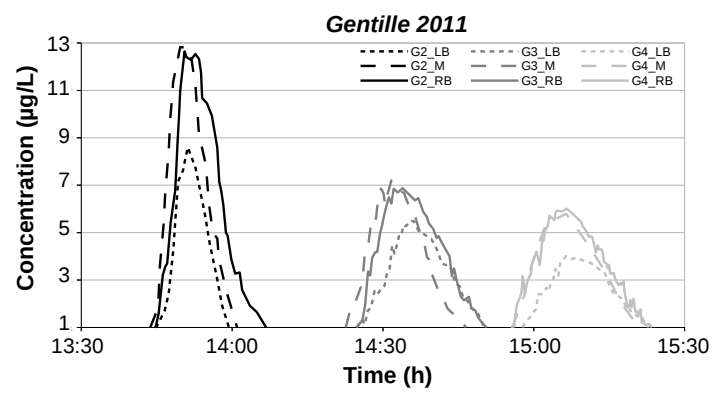

(a)

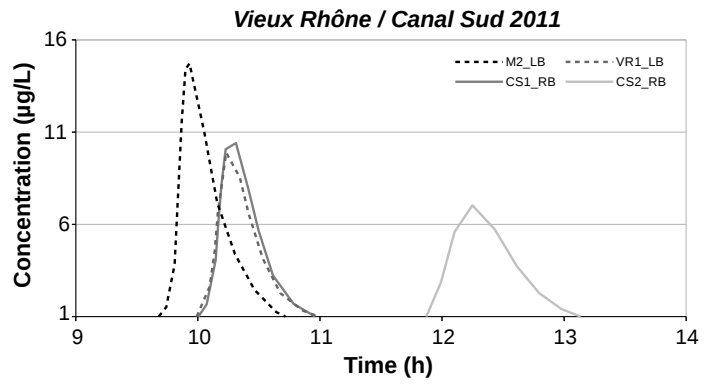

(c)

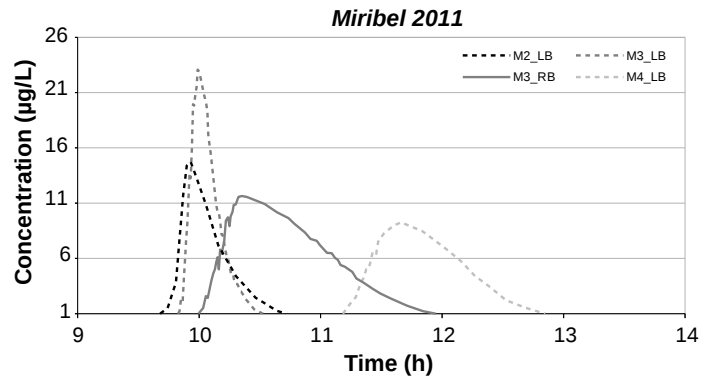

(b)

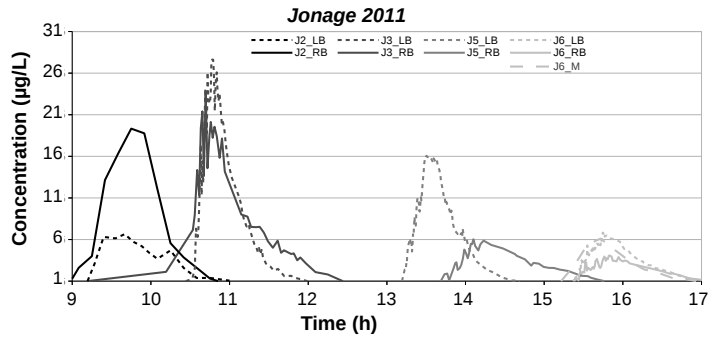

(d)

Figure 3: Breakthrough curves monitored during the 2011 tracer experiments along the Gentille canal (a, GE11), the Jonage canal (b, JN11), the Miribel canal (c, MI11) and the Vieux-Rhône and Canal Sud area (d, MI11). The locations of all the stations are presented in Fig. 2.

$L_{x}$ values reported in Table 4, compared to the distances from injection to monitoring positions, confirm that mixing was complete in 2001, and at least partially achieved in 2011.

In the Jonage canal in 2000, the distance between the injection point $\mathrm{A} 1$ and the monitoring positions is lower than $L_{x}$. It was not possible to compare the masses at the right and left banks, as the samples were taken at only one point of the section. Based on our observations in 2011, we nevertheless assumed that mixing was at least partially achieved at A2 (Fig. 2b). The difference between the injected mass and the masses recorded at A2 may be explained either by a loss of tracer, or by the incomplete recording of the breakthrough curve tail.

In 2011 in the Jonage canal, by comparing the intensity and arrival time of the tracer cloud (Fig. 3d), we conclude that the complete mixing was acceptably achieved at $\mathrm{J} 3$ point. However, since the distance to injection point, $L_{i}$, was even shorter than in 2001, while $L_{x}$ is even larger than for 2001, we must acknowledge that mixing and equilibrium were certainly only partially matched. Nevertheless, the experimental data obtained at J3 and at J6 allow to compute the $D_{L}$ value for this reach. Data in J5 are more difficult to use, especially because in J5-RB the fluorimeter was located too close to the bank, and not sufficiently exposed to the mainstream tracing.

\section{Experimental methods and results}

\subsection{Quantification of longitudinal dispersion from tracing results}

In the equilibrium zone, the average dispersion coefficient may be estimated from records collected upstream and downstream of a hydraulically homogeneous reach. Such homogeneous reaches are river sections with no bifurcations or confluences and with nearly uniform hydraulic characteristics (velocity, water depth, width, and flow resistance as quantified by the Strickler coefficients, $K_{s}$, of the calibrated hydraulic model). The change of moments method [49, 19, 25], the Chatwin method [10, 11], the routing procedure [20] or the use of a numerical modelling tool are different methods commonly used for the determination of $D_{L}$ from experimental data. Fischer [19] as well as Seo and Baek [42] mentioned that the change of moment method, though theoretically exact for any initial distribution of a finite tracer cloud, 


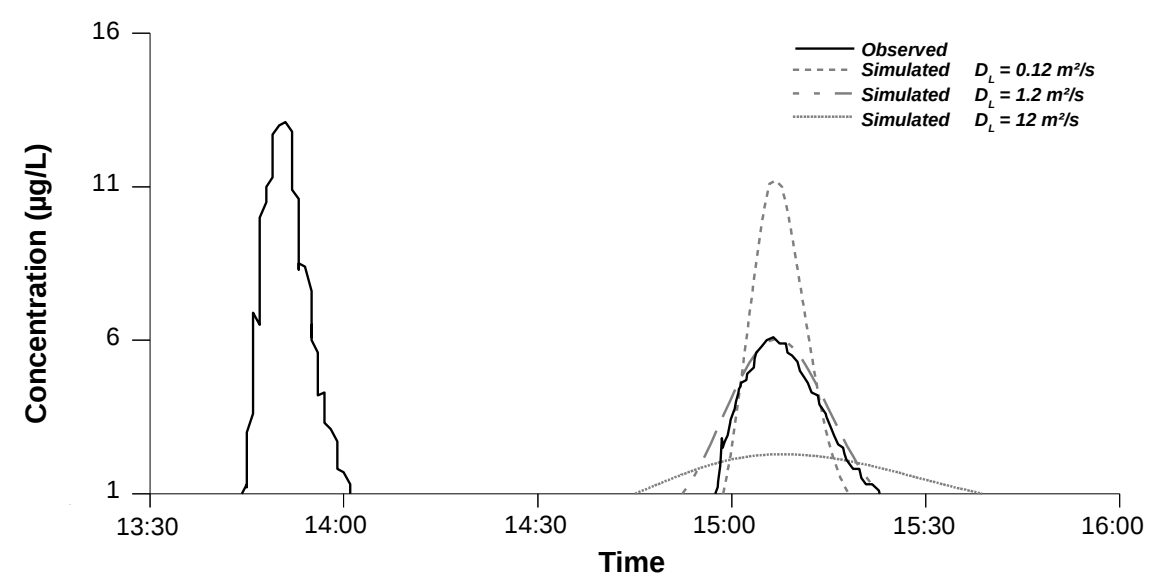

Figure 4: Fit-by-eye procedure to determine the $D_{L}$ parameter using the numerical model over a homogeneous reach: example of the data supplied by fluorescent tracer experiments in the Gentille canal in 2011 (GE11).

may be difficult to apply to field results because of long tails in the measured distributions. The change of moment method also assumes that the flow is uniform, steady throughout the whole reach. It is therefore advised to check the results with the routing procedure. However, Fischer [19] explained that the routing procedure cannot be applied analytically without some uncomfortable approximations, and that it would be better to solve it numerically, which is actually equivalent to applying a 1-D numerical model.

In this study, we used the 1-D numerical model to explicitly determine the experimental value for $D_{L}$ in homogeneous reaches. The concentration breakthrough curve measured at the upstream cross-section was set as an upstream boundary condition into the 1-D numerical model in order to route the tracer cloud all the way to the downstream section. The longitudinal dispersion coefficient was calibrated to get the best agreement of the results with the concentration breakthrough curve measured at the downstream cross-section. A simple fit-by-eye procedure was followed (Fig. 4), which was proved by Wörman and Wachniew [51] to yield reliable results and to be difficult to improve using automated fitting procedure. From repeatability tests, the accuracy of the fit-by-eye procedure was estimated to range from 5\% to $10 \%$ of the obtained longitudinal dispersion coefficient, $D_{L}$, which is negligible compared to the differences observed with the results of other estimation methods.

Such a methodology implies an accurate hydraulic calibration of the model in order to reduce the uncertainty related to a poor estimation of the advective effects. The hydraulic performance of the model was checked by comparing velocities given by the model, with velocities recorded by ADCP and observed peak-to-peak velocities along uniform reaches (Table 3). It should be noted that $U_{\text {model }}$ and $U_{A D C P}$ are local velocities at a given position along the river whereas $U_{\text {cloud }}$ is a spatially averaged velocity estimated between two monitoring points. In all experiments, simulated velocities are similar to observed velocities, which validated that the hydraulic calibration of the model was acceptable.

It seems logical to use the model to estimate longitudinal dispersion coefficient values that are to be used in the same model, i.e. applying exactly the same computational assumptions. However, as the easiest and the most traditional method, the change of moment method was also applied to our tests, following Eq. 75 of Fischer [19]:

$$
D_{L, m m t}=\frac{1}{2} U^{2} \frac{\sigma_{t, 2}^{2}-\sigma_{t, 1}^{2}}{\bar{t}_{2}-\bar{t}_{1}}
$$

where $U$ is the cross-sectional average velocity estimated from the reach length and the times, $\bar{t}_{1}$ and $\bar{t}_{2}$, of the centroids of the upstream and downstream breakthrough curves, respectively. The variance, $\sigma_{t}$, of each breakthrough curve is computed as the second central moment of each curve.

\subsection{The ADCP velocity survey method}

Building on the works by Fischer et al. [22], different authors [9, 43, 31] recently applied the following equation to the discrete sampling of velocity and depth made by ADCP in order to estimate the longitudinal 
Table 3: Comparison of velocities computed reach by reach using the numerical model $\left(U_{\text {model }}\right)$, ADCP measurements $\left(U_{A D C P}\right)$ and tracer experiments $\left(U_{\text {cloud }}\right)$. Acronyms standing for tracer experiments and sites are presented in Fig. 2.

\begin{tabular}{l|ll|ll|ll} 
& \multicolumn{2}{|l|}{$U_{\text {model }}$} & \multicolumn{2}{|l|}{$U_{\text {ADCP }}$} & $U_{\text {cloud }}$ & \\
& Site & {$[\mathrm{m} / \mathrm{s}]$} & Site & {$[\mathrm{m} / \mathrm{s}]$} & Reach & {$[\mathrm{m} / \mathrm{s}]$} \\
\hline GE11 & G3 & 0.25 & & & G2 $\rightarrow \mathrm{G} 3$ & 0.28 \\
& G4 & 0.24 & G4 & 0.26 & G3 $\rightarrow \mathrm{G} 4$ & 0.25 \\
\hline MI11 & M1 & 0.65 & M1 & 0.55 & M1 $\rightarrow \mathrm{M} 3$ & 0.70 \\
& M3 & 0.81 & M3 & 0.76 & & \\
\hline VR11 & VR1 & 0.57 & VR1 & 0.66 & M2-LB $\rightarrow$ VR1-LB & 0.75 \\
\hline CS11 & CS1 & 0.54 & CS1 & 0.50 & CS1-RB $\rightarrow$ CS2-RB & 0.73 \\
\hline JN11 & J1 & 0.57 & J1 & 0.59 & J2 $\rightarrow \mathrm{J} 3$ & 0.55 \\
\hline
\end{tabular}

dispersion due to the transverse velocity gradient:

$$
D_{L, t}=-A \int_{0}^{W}\left\{\overline{u^{\prime}} h \int_{0}^{y}\left[\frac{1}{D_{y} h} \int_{0}^{y^{\prime}} \overline{u^{\prime}} h \mathrm{dy}^{\prime \prime}\right] \mathrm{dy^{ \prime }}\right\} \mathrm{dy}
$$

with $A$ the wetted area of the cross-section, $y$ the transverse position varying from 0 to $W$, the river width, $\overline{u^{\prime}}$ the local depth-average streamwise velocity difference from the cross-sectional mean velocity, $U, h$ the local flow depth, and $D_{y}$ the transverse mixing coefficient. The latter parameter is usually assessed with the following approximation [22]:

$$
D_{y}=0.6 u_{*} h
$$

where $u_{*}$ is the local shear velocity. Recalling that the coefficient in Eq. 7 may vary from 0.3 to 0.9 for natural channels [39], the related uncertainty in the $D_{L, t}$ estimate can easily reach $100 \%$.

In uniform flows with known longitudinal slope, $J, u_{*}$ can be assumed to be roughly the same across the river and equal to $U_{*}=\sqrt{\rho R J}$, with $\rho$ the water density and $R$ the hydraulic radius. $D_{L, t}$ is proportional to $1 / \sqrt{J}$ and thus is not very sensitive to the slope. In the case described in this paper, $J$ was derived from 1-D numerical models. Alternatively, vertical velocity profiles measured by ADCP can be regressed to derive the local value for $u_{*}$ from the logarithmic slope of the law of the wall, for a fully developed uniform turbulent layer. These local $u_{*}$ values may be either used directly in Eq. 6 or beforehand cross-section averaged (see the manual of the AdcpXP software, Kim [31]). We prefer using the bulk shear velocity, $U_{*}$, since the derivation of local $u_{*}$ from ADCP vertical profiles may lack of accuracy, especially due to the near-bottom unmeasured area.

Kim [31] further stresses that in situations for which the longitudinal dispersion is mainly driven by the vertical velocity gradient, rather than the transverse velocity gradient, the local longitudinal dispersion coefficient, $D_{L}$, can also be derived from ADCP data, as [49]:

$$
D_{L, v}=-\frac{1}{h} \int_{0}^{h}\left\{u^{\prime} \int_{0}^{z}\left[\frac{1}{D_{z}} \int_{0}^{z^{\prime}} u^{\prime} \mathrm{dz} z^{\prime \prime}\right] \mathrm{dz}\right\} \mathrm{dz}
$$

with $z$ the vertical position above the bed varying from 0 to $h, u^{\prime}$ the local streamwise velocity difference from the depth-average velocity, and $D_{z}$ the vertical mixing coefficient, which may be approximated as [22]:

$$
D_{z}=0.067 u_{*} h
$$

The longitudinal dispersion coefficient due to transverse velocity gradients $D_{L, t}$ (Eq. 6) is representative of the transport of a fully mixed tracer along a uniform reach, and can typically be used in 1-D hydraulic models. In contrast, the longitudinal dispersion coefficient due to vertical velocity gradients $D_{L, v}$ (Eq. 8) is more appropriate for a tracer slug which would be fully mixed vertically but with limited transversal extension. For intermediate situations, which are likely to occur for tracer experiments in large rivers, 
the longitudinal dispersion is expected to lie in between both estimates. To apply the ADCP method, we used the AdcpXP software developed by Kim [31], which computes the $D_{L, t}$ and $D_{L, v}$ values by applying Eqs. 6 and 8 to velocities throughout the whole cross-section: velocities in unmeasured near-bottom and near-edges areas are extrapolated based on a $1 / 6$ power function and included in the computation.

\subsection{Experimental dispersion values}

The morphological and hydraulic characteristics of the uniform reaches for the different tracer experiments are given in Table 4 as well as the dispersion coefficients obtained with the tracing and ADCP methods. For three of the homogeneous reaches, especially the prismatic Gentille canal (GE11), the dispersion coefficients obtained from the tracer experiments by fitting the 1-D model $\left(D_{L, \text { exp }}\right)$ or by applying the change of moment method $\left(D_{L, m m t}\right)$ are in very close agreement, within a few $\%$. The results of the change of moment method agree by no more than a factor 2 for all experiments except in the Canal Sud channel (CS11) where $D_{L, m m t}$ is roughly 5 times greater than $D_{L, \text { exp }}$. This can be explained because simulated velocities and depth are actually less uniform throughout that reach than in the others. Subsequently, the model calibration may be poorer in that CS11 reach. $D_{L, m m t}$ can be either lower or greater than $D_{L, e x p}$, which suggests that the 1-D model is not biased by excessive numerical dispersion. Dispersion values obtained using the 1-D model, $D_{L, \text { exp }}$, will be kept as the reference values precisely because they are consistent with the computational assumptions of the model to be calibrated.

The experimental results presented in this work are comparable to the data from literature (see Fig. 1, our data). The aspect ratio, $W / H$, of the homogeneous reaches ranges from 5 to 50 and the velocity ratio, $U / U_{*}$, is spread from 5 to 15 , which are situations commonly encountered on the Rhône River and similar medium-sized rivers. The $D_{L} /\left(H U_{*}\right)$ values obtained from the tracing method vary between 10 and 1000 .

Fig. 5 presents the dimensionless dispersion values obtained with the ADCP method versus the reference values obtained from tracing results. As expected, $D_{L, t}$ is always higher than $D_{L, v}$, and the discrepancy between the two values spreads from one to four orders of magnitude. This confirms that in most of our field cases, the longitudinal dispersion is mainly driven by the transverse velocity gradient, rather than by the vertical velocity gradient.

For all experiments with available ADCP data, $D_{L, t}$ is in the same order of magnitude as the value obtained from the tracing method, which suggests that the ADCP method may be an acceptable surrogate to the costly tracing method. Except for the JN11 experiment, $D_{L, t}$ is always lower than $D_{L, \text { exp }}$. Some explanations can be proposed to such underestimating trend. First, the ADCP method relies on velocity recorded throughout the whole cross-section. In the GE11 case, the transversal velocities measured by the ADCP at G4 present a very flat profile and unmeasured areas near edges represent almost $15 \%$ of the cross-section. Then, the transversal velocity gradient may not be well captured in such a situation, leading to an underestimation of the $D_{L, t}$ value. Moreover, the spatial resolution of the ADCP grid and the spatial averaging by the software may also lead to underrating of the transversal gradient. Both types of issues might be mitigated by fitting a continuous function to the transverse profile of the longitudinal velocity, as Seo and Baek [42] did using the beta probability distribution function.

We also highlighted in Section 3.3 that partial mixing of the tracer should be reminded in some reaches, which could have an effect on the $D_{L}$ value from tracer experiment. Besides, the more important differences between $D_{L, t}$ and tracer experiment results in CS11 and, to a lesser extent, in VR11 certainly arise because ADCP measurements were conducted in cross-sections that were not fully representative of the reach-averaged hydraulic conditions. Nevertheless, for the cases presented in Fig. 5, the ADCP method considering the transverse velocity gradient as the main driver of the longitudinal dispersion produces dispersion estimates, $D_{L, t}$, that are in good agreement with the values obtained from tracer experiment.

\section{Calibrating dispersion in 1-D hydraulic models}

\subsection{Performance of dispersion predictors}

For each tracer experiment, the six formulae from the literature presented in Table 1 were applied to compute the longitudinal dispersion coefficient, $D_{L}$. The results are presented in Fig. 6 . The four scores already presented in Section 2.2 were used to evaluate the performance of the formulae in predicting the dispersion values from our tracer experiments (Table 5). 


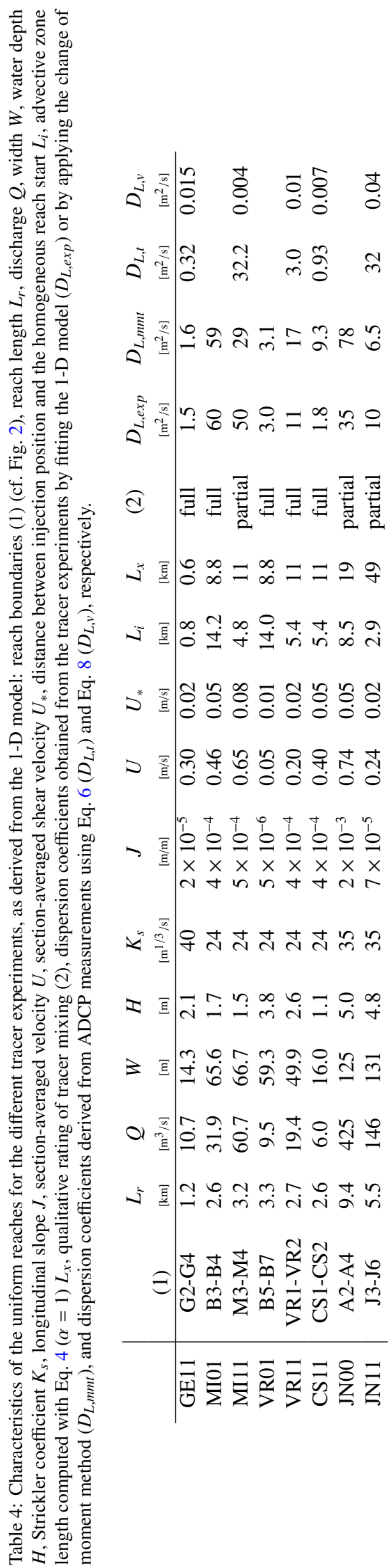




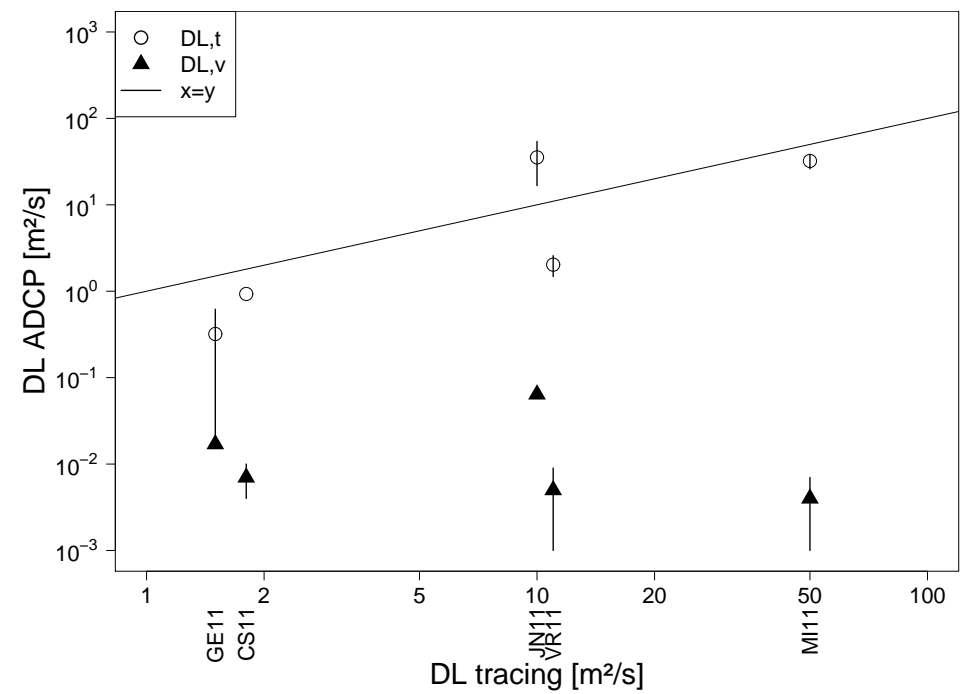

Figure 5: ADCP-based longitudinal dispersion coefficients $\left(D_{L, t}, D_{L, v}\right)$ against the results of the tracer experiments. Error bars show the standard-deviation computed over the successive ADCP transects.

Table 5: Performances of the empirical formulae using our data from tracer experiments

\begin{tabular}{l|cccc} 
Authors / formula & mean(E) & $\operatorname{std}(\mathrm{E})$ & G2 (\%) & G5 (\%) \\
\hline & & & & \\
Elder [16] & -1.65 & 0.45 & 0 & 13 \\
Fischer [21] & 0.57 & 0.36 & 38 & 63 \\
Liu [34] & 0.25 & 0.28 & 50 & 88 \\
Iwasa and Aya [27] & 0.13 & 0.24 & 75 & 100 \\
Seo and Cheong [41] & 0.90 & 0.42 & 13 & 38 \\
Koussis and Rodriguez-Mirasol [32] & 0.27 & 0.28 & 50 & 100
\end{tabular}

The ranking of the formulae is generally very consistent with what was observed against the literature review provided in Section 2.2 (cf. Table 2). As observed by Fischer [19], the Elder [16] formula does not apply since it always underestimates the experimental values, from one to two orders of magnitude. The results from other formulae overestimate the experimental values from 10 to $100 \%$ on average, which is consistent with the findings of Seo and Baek [42].

Again, the formula of Iwasa and Aya [27] produces the best results, followed by that of Liu [34], and the formula of Fischer [21] shows poorer results. The main difference with the evaluation against literature data is that the formula of Koussis and Rodriguez-Mirasol [32] shows a performance as good as, if not better than, the formula of Liu [34]. On the other hand, the formula of Seo and Cheong [41] yields poorer results. It appears that the formulae for which the fit was mainly based on the parameter $W / H[34,27,32]$ are generally more appropriate for field data. On the contrary, formulae with a large $b$-value $[21,41]$ seem to be too sensitive to the calculation of $U / U *$, which often induces larger uncertainties especially in field data. Seo and Baek [42] showed that the formula of Seo and Cheong [41] would give larger estimates than other formulas when $W / H<40$.

\subsection{Uncertainty in modelling a pollution dynamics throughout a complex river network}

1-D hydraulic models of large river networks should be able to give reliable estimations of the pollution dynamics in terms of peak concentration and arrival time. Fig. 7 shows the simulation results of a pollution peak injected $29 \mathrm{~km}$ upstream of the Miribel-Jonage area. This example illustrates the necessity of using a well-calibrated hydrodynamic model for properly simulating a pollution dynamics through a complex 


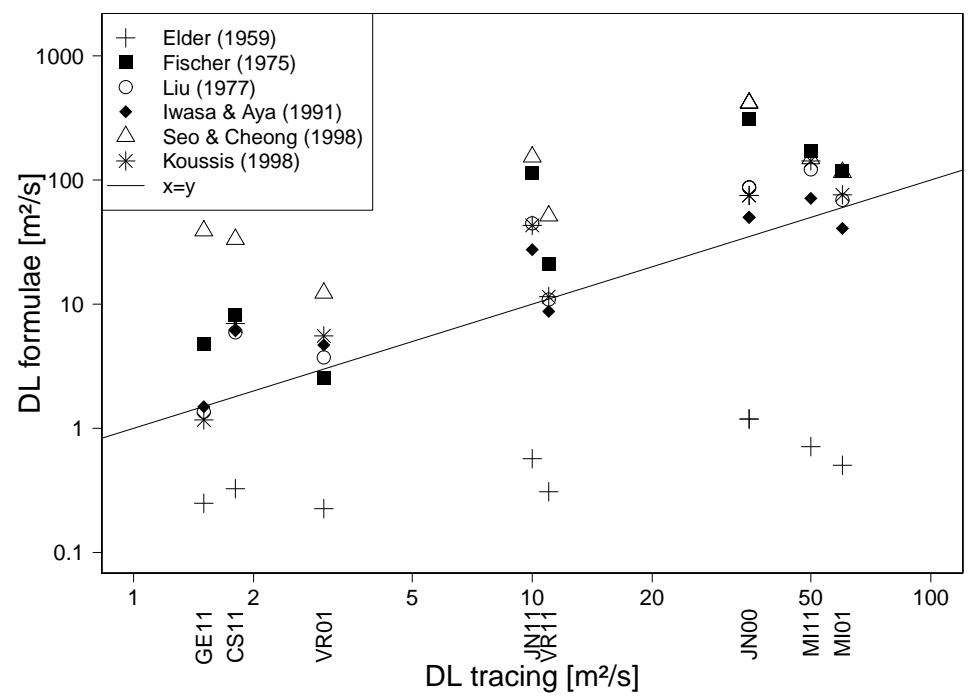

Figure 6: Longitudinal dispersion coefficients predicted by state-of-the-art formulae against the results of the tracer experiments.

multi-channel artificialized river system such as the Miribel-Jonage system. Indeed, the transformation of the pollution slug through the river network and hydraulic schemes would be impossible to reproduce with analytical models, even those involving a more detailed description of dispersion processes than the simple Fickian model. As the Mage-AdisTS model accounts for the contrasted propagation and dispersion in Miribel canal, Vieux-Rhône channel and Jonage canal with different dams, it is able to simulate the combination of the three pollution travel paths. This is the reason why two, sometimes three, concentration clouds can be distinguished in the breakthrough curve simulated at the downstream end of the river network (cf. Fig. 7).

We have to use a predictive formula, instead of experimental fixed dispersion values, because not all reaches in the river system were documented with tracer measurements, and some of them cannot be considered hydraulically homogeneous. Depending on the formula chosen to compute $D_{L}$, the breakthrough curves obtained downstream of the Miribel-Jonage area are widely different. Although we do not have experimental evidence to compare with the numerical tests shown in Fig. 7, we assume that the more realistic dispersion values are provided by the formulae that were best-ranked in the tests using the literature data (cf. Table 2), and a fortiori using our experimental data at the same site (cf. Table 5). Accordingly, we can assume that the more realistic signals are provided by the formulae of Iwasa and Aya [27], Liu [34], and Koussis and Rodriguez-Mirasol [32], which produce very similar results.

As expected, the formula of Elder [16] yields a much lower dispersion values, whereas the formula of Fischer [21] and, a fortiori, the formula of Seo and Cheong [41] yield higher dispersion values. The maximum concentration varies from $2 \mathrm{mg} / \mathrm{L}$ for the Elder formula to $1 \mathrm{mg} / \mathrm{L}$ for the Seo and Cheong formula. The difference in predicted dispersion also induces changes in the temporal dynamics of the simulated pollution. As an effect of the widening of the three pollutant clouds, the maximum concentration is simulated $\sim 5$ hours earlier with the Seo and Cheong formula, compared to the less dispersive results obtained with the the formulae of Iwasa and Aya, Liu, and Koussis and Rodriguez-Mirasol.

\section{Conclusions}

The issues related to the calibration of pollutant dispersion in 1-D hydraulic models of large river networks were investigated using field cases, ranging from a simple trapezoidal canal to a complex river network. Most of the breakthrough curves we obtained from our fluorescent tracer experiments show some skewness, even in the Gentille canal, where transient storage is unlikely to occur. As already mentioned by Rutherford [39], such skewness is usually inherited from the mixing process in the advective zone, before the equilibrium zone is established, which should not be automatically assigned to transient storage effects. 


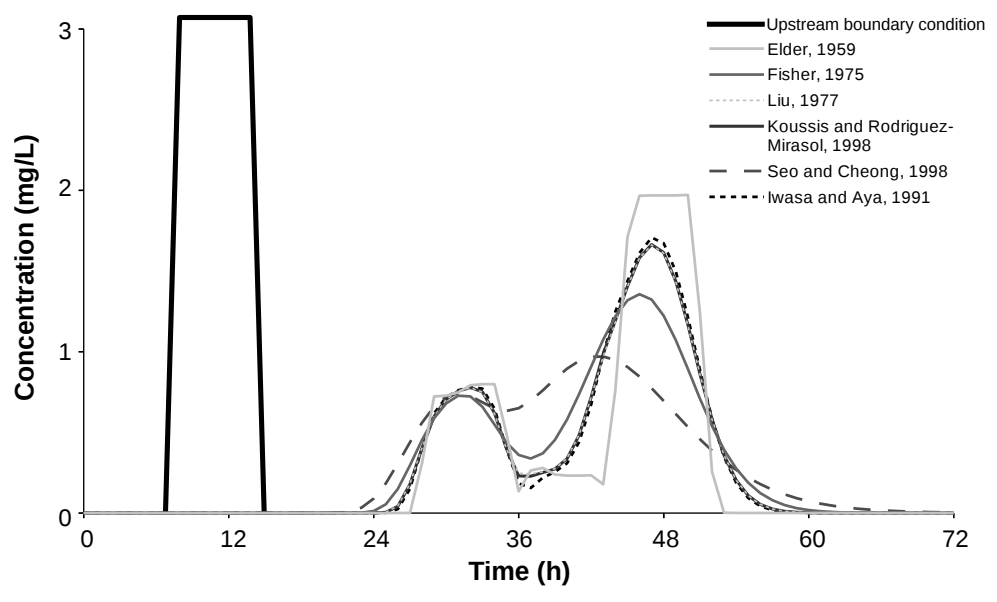

Figure 7: Simulated propagation of a pollution peak through the Miribel-Jonage river network, using six different formulae to compute $D_{L}$.

In eight river reaches with nearly uniform hydraulic conditions and fully or partially achieved tracer mixing and dispersive equilibrium, experimental dispersion values were quantified with the Mage-AdisTS 1-D model using both the change of moment method and a simple fit-by-eye procedure. The obtained experimental dispersion values are consistent with the data available in the literature. However, the ideal conditions may be very difficult to fulfil in large channels with artificial structures and bifurcations such as the Miribel-Jonage system. Even using fluorescent tracers and immersed fluorimeters, such experiments in large rivers require a huge amount of time, work and money, and cannot be extended to a wide range of sites and hydraulic conditions.

While the ADCP method was already introduced and applied by others, this study is to our best knowledge the first one to report a comparison of ADCP dispersion results in rivers with tracer experiments and application of a 1-D hydraulic model. The ADCP method provided values which were in valuable agreement with the tracer experiments, in spite of the uncertainties on parameters such as the turbulent mixing coefficient or the energy slope of the flow. Through the $D_{L, t}$ and $D_{L, v}$ estimates, the ADCP method also provides a quantification of the relative importance of transversal versus vertical velocity gradients in controlling the longitudinal dispersion. As expected in rivers, the latter dispersion term was always found to be negligible before the former one. Since it is a much more cost-efficient method than tracer experiments, the ADCP-based method appears as a promising technique for improving the calibration of dispersion coefficients in pollutant transport models of large river systems. Actually, a lot of ADCP data acquired by hydrometry staff are already available at many gauging sites in most rivers, including the largest ones in the world where tracing is impossible to perform.

The lack of representativeness of the experimental data set used to calibrate the formulae used to predict longitudinal dispersion coefficients in 1-D models is an important concern, especially for modelling large river networks. With the exception of the Elder [16] formula, all the tested predictive formulae yielded dispersion values that are consistent with the reference values derived from tracer experiments, though generally overestimated by up to one log decade. The best results were obtained with the formula from Iwasa and Aya [27], followed by the formula of Liu [34].

Transient storage effects on the longitudinal dispersion are not accounted for in AdisTS, as is the case in most common 1-D hydraulic models with a water quality module, such as MIKE11 [14] for instance. Implementing them in 1-D river models is still an interesting research perspective. An important issue is that calibration fits that account for transient storage effects (see e.g. Cheong and Seo [12]) may provide significantly different values for the Fickian longitudinal dispersion coefficient. This observation reminds us again that dispersion coefficient values depend on the simulation method used, and that ideally they should be calibrated using the same model in which they are to be used, as was done in this study. So far, introducing transient storage in 1-D hydraulic models might be a negligible improvement, in case the 
mainstream longitudinal dispersion coefficient is not parameterized accurately based on an appropriate predictive formula.

\section{Acknowledgements}

This work has been conducted in the framework of the Rhône Sediment Observatory project and was partly funded by the Plan Rhône. The PhD scholarship of Marina Launay was granted by the Région Rhône-Alpes (convention number: 12-013144-01 for the PhD third year).

\section{References}

[1] Andries, E., Le Coz, J., Camenen, B., Faure, J.-B., and Launay, M. (2011). Impact of dam flushes on bed clogging in a secondary channel of the Rhône river. Proceedings of RCEM (River, Coastal and Estuarine Morphodynamics), Beijing, China, $10 \mathrm{p}$.

[2] André, H., Audinet, M., Mazeran, G., and Richer, C. (1976). Hydrométrie pratique des cours d'eau. [Practical hydrometry in rivers]. Direction des études et des recherches d'Électricité de France (EDF), 88 p. (in French)

[3] André, J. and Molinari, J. (1976). Mises au point sur les différents facteurs physico-chimiques influant sur la mesure de traceurs fluorescents et leurs conséquences pratiques en hydrologie. [Clarifications on the various physico-chemical factors affecting the degree of fluorescent tracers and their practical implications in hydrology]. Journal of Hydrology, 30:257-285. (in French)

[4] Biron, P., Ramamurthy, A., and Han, S. (2004). Three-dimensional numerical modeling of mixing at river confluences. Journal of Hydraulic Engineering, 130(3):243-253.

[5] Bencala, K.E., and Walters, R.A. (1983). Simulation of Solute Transport in a Mountain Pool-and-Riffle Stream: A Transient Storage Model. Water Resources Research, 19(3):718-724.

[6] Bottacin-Busolin, A., Marion, Musner, T., Tregnaghi, M., and Zaramella M. (2011). Evidence of distinct contaminant transport patterns in rivers using tracer tests and a multiple domain retention model. Advances in Water Resources, 34:737-746.

[7] Boiten, W. (2000). Hydrometry. Francis and Taylor publishers, $257 \mathrm{p}$.

[8] Caplow, T., Schlosser, P., and Ho, D. (2004). Tracer study of mixing and transport in the upper Hudson River with multiple dams. Journal of Hydraulic Engineering, 130(12):1498-1506.

[9] Carr, M. and Rehmann, C. (2007). Measuring the dispersion coefficient with acoustic Doppler current profilers. Journal of Hydraulic Engineering, 133(8):977-982.

[10] Chatwin, P. (1971). On the interpretation of some longitudinal dispersion experiments. Journal of Fluid Mechanics, 48(4):689702.

[11] Chatwin, P. (1980). Presentation of longitudinal dispersion data. Journal of Hydraulic Divisions, 106(1):71-83.

[12] Cheong, T., and Seo, I. (2003). Parameter estimation of the transient storage model by a routing method for river mixing processes. Water Resources Research, 39(4):1-11.

[13] Davis, S., Thompson, G., Bentley, H., and Stiles, G. (1980). Ground-water tracers - A short review. Ground Water, 18(1):14-23.

[14] DHI (2009). MIKE11 - A Modelling System for Rivers and Channels. Reference Manual, 524 p.

[15] Duarte, A. A. and Boaventura, R. A. (2008). Dispersion modelling in rivers for water sources protection, based on tracer experiments. Case studies. In Mastorakis, N.E., Poulos, M., Mladenov, V., Bojkovic, Z., Simian, D. and Kartalopoulos, S., editor, Proc. 2nd Int. Conf. on Waste Management, Water Pollution, Air Pollution, Indoor Climate, Energy and Environmental Engineering Series, pages 205-210, Corfu, Greece.

[16] Elder, J. (1959). The dispersion of marked fluid in turbulent shear flow. Journal of Fluid Mechanics, 5(4):544?560.

[17] Fassnacht, S. (1997). A multi-channel suspended sediment transport model for the Mackenzie Delta, Northwest Territories. Journal of Hydrology, 197:128-145.

[18] Field, M., Wilhem, R., Equilan, J., and Aley, T. (1995). An assessment of the potential adverse properties of fluorescent tracer dyes used for groundwater tracing. Environmental Monitoring and Assessment, 38:7596.

[19] Fischer, H. (1966). Longitudinal dispersion in laboratory and natural streams. Report KH-R-12, Keck Laboratory of hydraulics and water resources, California Institute of Technology, Pasadena, California, USA. 265 p.

[20] Fischer, H. (1968). Dispersion predictions in natural streams. J. Sanit. Eng. Div., ASCE, 94(SA5):927-943.

[21] Fischer, H. (1975). Discussion of simple method for predicting dispersion in stream by R. S. McQuivey and T. N. Keefer. Journal of Environmental Engineering Division, 101(3):453?455.

[22] Fischer, H., List, E., Koh, R., Imberger, J., and Brooks, N. (1979). Mixing in Inland and Coastal Waters. Academic Press, New York. 497 p.

[23] Flury, M. and Wai, N. (2003). Dyes as tracers for vadose zone hydrology. Reviews of Geophysics, 41:1002.

[24] Gooseff, M.N., Hall JR., R.O., and Tank, J.L. (2005). Relating transient storage to channel complexity in streams of varying land use in Jackson Hole, Wyoming. Water Resources Research, 43(W01417):1-10.

[25] Ho, D., Schlosser, P., and Caplow, T. (2002). Determination of longitudinal dispersion coefficient and net advection in the tidal Hudson River with a large-scale, high resolution SF6 tracer release experiment. Environmental Science $\mathcal{E}$ Technology, 36(15):3234-3241.

[26] Hubbard, E., Kilpatrick, F., Martens, L., and Wilson, J. (1982). Measurement of time of travel and dispersion in streams by dye tracing. Techniques of Water-Resources Investigations, vol. 3, 44 p.

[27] Iwasa, Y. and Aya, S. (1991). Predicting longitudinal dispersion coefficient in open channel flows. In Int. Symp. on Environmental Hydraulics, pages 505-510, Hong-Kong, China.

[28] Jobson, H. (1997). Predicting travel time and dispersion in rivers and streams. Journal of Hydraulic Engineering-ASCE, 123(11):971-978. 
[29] Jobson, H. (2001). Predicting river travel time from hydraulic characteristics. Journal of Hydraulic Engineering-ASCE, 127(11):911-918.

[30] Kilic, S.G., and Aral, M.M. (2009). A fugacity based continuous and dynamic fate and transport model for river networks and its application to Altamaha River. Science of the total environment,407(12):3855-3866.

[31] Kim, D. (2012). Assessment of longitudinal dispersion coefficients using Acoustic Doppler Current Profilers in large river. Journal of Hydro-Environment Research, 6(1):29-39.

[32] Koussis, A. and Rodriguez-Mirasol, J. (1998). Hydraulic estimation of dispersion coefficient for streams. Journal of Hydraulic Engineering-ASCE, 124(3):317-320.

[33] Leibundgut, C., Maloszewski, P., and Külls, C. (2009). Tracers in Hydrology. Wiley-Blackwell.

[34] Liu, H. (1977). Predicting dispersion coefficient of streams. Journal of the Environmental Engineering Division, 103(1):59-69.

[35] Magazine, M., Pathak, S. and Pande, P. (1988). Effect of bed and side roughness on dispersion coefficient in natural streams. Journal of Hydraulic Engineering, 114(7):766-782.

[36] Marion, A., Zaramella, M., and Bottacin-Busolin, A. (2008). Solute transport in rivers with multiple storage zones: The STIR model. Water Resources Research, 44(10), W10406.

[37] Nordin Jr., C.F.N. and Troutman, B. M. (1980). Longitudinal dispersion in rivers: The persistence of skewness in observed data. Water Resources Research, 16(1):123-128.

[38] Rowinski, P., Guymer, I., and Kwiatkowski, K. (2008). Response to the slug injection of a tracer-a large-scale experiment in a natural river. Hydrological Sciences Journal, 53(6):1300-1309.

[39] Rutherford, J. (1994). River Mixing. Wiley. 362 p.

[40] Scheidegger, A. (1961). General theory of dispersion in porous media. Journal of Geophysical Research, 66:3273-3278.

[41] Seo, I. and Cheong, T. (1998). Predicting longitudinal dispersion coefficient in natural streams. Journal of Hydraulic Engineering-ASCE, 124(1):25-32.

[42] Seo, I. and Baek, K. (2004). Estimation of the longitudinal dispersion coefficient using the velocity profile in natural streams. Journal of Hydraulic Engineering-ASCE, 130:227-236.

[43] Shen, C., Niu, J., Anderson, E., and Phanikumar, M. (2010). Estimating longitudinal dispersion in rivers using Acoustic Doppler Current Profilers. Advances in Water Resources, 33(6):615-623.

[44] Smart, P. (1984). A review of the toxicity of twelve fluorescent dyes used for water tracing. The National Speleological Society Bulletin, 46:21.

[45] Smart, P. and Laidlaw, I. (1977). An evaluation of some fluorescent dyes for water tracing. Water Resources Research, 13 (1): $15-33$.

[46] Souhar, O., and Faure, J.-B. (2009). Approach for uncertainty propagation and design in Saint Venant equations via automatic sensitive derivatives applied to Saar river. Canadian Journal of Civil Engineering 36 (7), 1144-1154.

[47] Steinheimer, T. and Johnson, S. (1986). Investigation of the possible formation of diethylnitrosamine resulting from the use of rhodamine WT dye as a tracer in river waters. USGS WSP 2290, 2290:37.

[48] Szeftel, P., Moore, R.D., and Weiler, M. (2011). Influence of distributed flow losses and gains on the estimation of transient storage parameters from stream tracer experiments. Journal of Hydrology, 396, 277-291.

[49] Taylor, G. (1954). The dispersion of matter in turbulent flow through a pipe. In Royal society, volume A, pages 446-468.

[50] Wilson, J., Cobb, E., and Kilpatrick, F. (1986). Fluorometric procedures for dye tracing. Techniques of Water-Resources Investigations, vol. $3,31 \mathrm{p}$.

[51] Wörman, A. and Wachniew, P. (2007). Reach scale and evaluation methods as limitations for transient storage properties in streams and rivers. Water Resources Research, 43, W10405. 